\title{
Colloidal toxic trace metals in urban riverine and estuarine waters of Yantai City, southern coast of North Yellow Sea
}

\author{
Yuxi Lu ${ }^{\mathrm{a}, \mathrm{b}}$, Xuelu Gao ${ }^{\mathrm{a}, \mathrm{b}, *}$, Jinming Song ${ }^{\mathrm{b}, \mathrm{c}, \mathrm{d}}$, Chen-Tung Arthur Chen ${ }^{\mathrm{e}}$, Jinling Chu ${ }^{\mathrm{a}}$ \\ ${ }^{a}$ CAS Key Laboratory of Coastal Environmental Processes and Ecological Remediation, Yantai Institute of Coastal Zone Research, Chinese Academy of Sciences, Yantai, \\ Shandong 264003, China \\ ${ }^{\mathrm{b}}$ University of Chinese Academy of Sciences, Beijing 100049, China

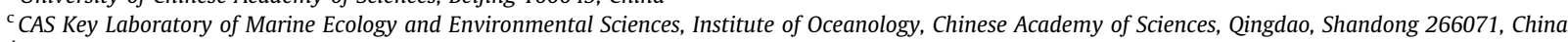 \\ ${ }^{\mathrm{d}}$ Function Laboratory of Marine Ecology and Environmental Sciences, Qingdao National Laboratory of Marine Science and Technology, Qingdao, Shandong 266237, China \\ ${ }^{\mathrm{e}}$ Department of Oceanography, National Sun Yat-sen University, Kaohsiung 80424, Taiwan
}

\section{H I G H L I G H T S}

- An optimized method for determining aquatic colloidal metals was provided.

- The real water samples were successfully tested and obtained excellent results.

- Colloidal metal heterogeneity in two urban rivers of coastal China was studied.

- Strong ligand, mixing and flocculation co-regulated colloidal dynamics in urban rivers.

\section{A R T I C L E I N F O}

\section{Article history:}

Received 27 August 2019

Accepted 27 October 2019

Available online 21 November 2019

Editor: Filip M.G. Tack

\section{Keywords:}

Aquatic environment

Dissolved trace metal

Centrifugal ultrafiltration

Membrane calibration

Geochemical features
G R A P H I C A L A B S T R A C T

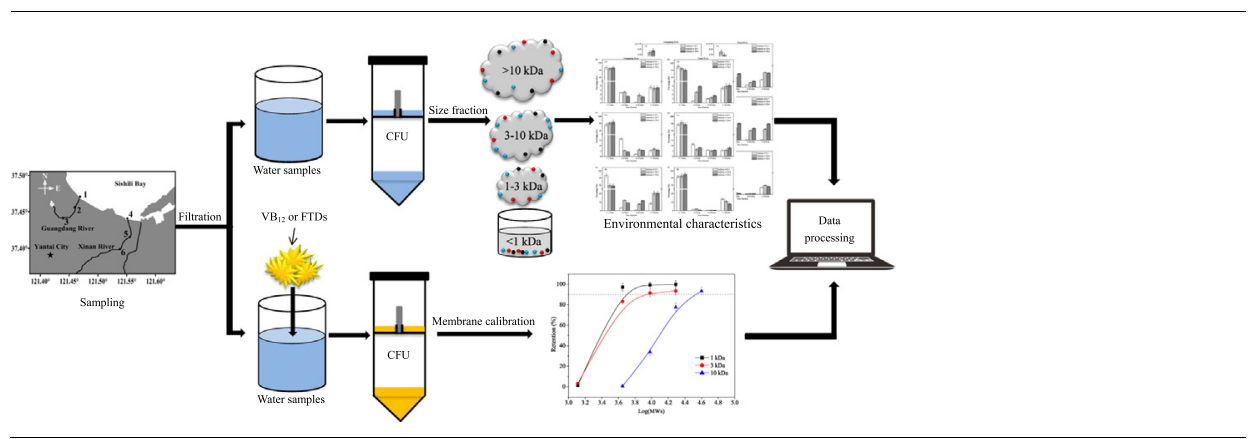

\section{A B S T R A C T}

The environmental characteristics of colloidal toxic trace metals $\mathrm{Cd}, \mathrm{Cu}$ and $\mathrm{Pb}$ in riverine and estuarine waters collected from two urban rivers of Yantai City in eastern China, the Guangdang and Xin'an Rivers, were investigated using a modified centrifugal ultrafiltration (CUF) method in conjunction with acid extraction and inductively coupled plasma mass spectrometry. The target metals in dissolved pool were divided into four CUF fractions, i.e. $<1 \mathrm{kDa}, 1-3 \mathrm{kDa}, 3-10 \mathrm{kDa}$ and $10 \mathrm{kDa}-0.2 \mu \mathrm{m}$, and the results showed that colloidal $\mathrm{Cd}, \mathrm{Cu}$ and $\mathrm{Pb}$ were dominated by 1-10 kDa (1-3 and 3-10 kDa), 1-3 kDa and $10 \mathrm{kDa}-0.2 \mu \mathrm{m}$ fractions, respectively. The coagulation/flocculation of low-molecular-weight (1$10 \mathrm{kDa}$ ) colloidal $\mathrm{Cd}$ and $\mathrm{Cu}$ in the estuaries was obvious and strong, while the enrichment of dissolved $\mathrm{Pb}$ in the $10 \mathrm{kDa}-0.2 \mu \mathrm{m}$ fraction may be mainly related to its biogeochemical interactions with Feoxides, which is easy to occur in macromolecular colloids. In addition, the actual molecular weight cutoffs (MWCOs) of the three used CUF units with nominal MWCOs of 1,3 and $10 \mathrm{kDa}$ were determined to be 4.9, 8.5 and $33.9 \mathrm{kDa}$, respectively, indicating that membrane calibration is essential for explaining the actual fraction of dissolved trace metals and verifying the integrity of ultrafiltration membrane. Overall, the results in this study provide a further understanding of the heterogeneity in biogeochemical features, migration and fate of toxic trace metals in aquatic ecosystems, especially that of the river-sea mixing zone.

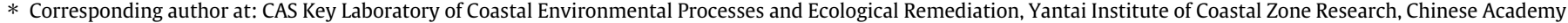
of Sciences, Yantai, Shandong 264003, China.

E-mail address: xlgao@yic.ac.cn (X. Gao).
} 


\section{Introduction}

Trace metals exist in various physical and chemical forms in natural water systems and play an important role in the biogeochemical cycle (Li et al., 2015). Based on size, metals are divided into three fractions, i.e. particulate, colloidal and truly dissolved phases (Lead and Wilkinson, 2006). Within these three forms, dissolved phase is usually defined as the portion that can pass through the $0.45 \mu \mathrm{m}$ filter, but this operational definition ignores the colloidal phase in water system (Waeles et al., 2008).

The specific size range of the colloidal state has not been uniformly defined in previous studies, and the main pore diameters of the filters used for pre-filtering seawater were 0.2 (Guo et al., 2000), 0.45 (Zhou et al., 2016), and $1 \mu \mathrm{m}$ (Zhang et al., 2007). Meanwhile, a variety of techniques have been successfully applied for the separation of colloidal materials, such as cross-flow ultrafiltration (Liu et al., 2013), centrifugal ultrafiltration (Xu et al., 2018) and field flow fractionation (Zhou and Guo, 2015). Due to the small amount of sample, easy operation and low cost, centrifugal ultrafiltration (CUF) is considered to be a high-efficiency colloidal substance separation technology. The CUF is also one of the few separation methods that do not require auxiliary reagents (Burba et al., 1998). But no matter which size standard or separation technique was used, the study found that a large part of the dissolved metal was present in the macromolecular organic complex state (i.e. the colloidal phase), which largely controls the operation of the marine ecosystem (Wen et al., 2011). Therefore, the determination of the metal forms in aquatic systems is critical for the understanding of the geochemical cycle and bioavailability of trace metals (Liu et al., 2013; Cornu et al., 2018). Among them, as an important transition zone between freshwater and seawater, the strong physico-chemical behaviors and hydrodynamic gradients of the estuary zone could have great impact on metal transfer and geochemical cycles (Waeles et al., 2008). Although previous studies have reported colloidal metal transfer as a function of salinity in the estuary area, studies of transfer behavior between various low-molecular-weight (LMW) colloidal fractions (1$10 \mathrm{kDa}$ ) are particularly inadequate (Waeles et al., 2008).

In this study, the distribution of $\mathrm{Cu}, \mathrm{Pb}$ and $\mathrm{Cd}$ in four size fractions (i.e. $<1 \mathrm{kDa}, 1-3 \mathrm{kDa}, 3-10 \mathrm{kDa}$ and $10 \mathrm{kDa}-0.2 \mu \mathrm{m}$ ) in estuaries of the Guangdang River and the Xin'an River in the northern part of the Shandong Peninsula (Eastern China) is reported. The two rivers are located in typical Chinese coastal urban systems (Zhang et al., 2016), and occupy an important area of the Shandong Peninsula Blue Economic Zone which is integrated in the national development strategy (Huang et al., 2013). The originality of this work is the combined use of CUF, acid extraction and ICP-MS to separate and measure trace elements in colloidal/dissolved fractions along an estuarine salinity gradient. Besides, the molecular weight cutoffs (MWCOs) of the ultrafiltration membranes used in this study were calibrated using standard macromolecules in combination with UV spectrophotometry and high performance liquid chromatography.

\section{Material and methods}

\subsection{Reagents}

The mixed standard solutions for three target elements ( $\mathrm{Cd}, \mathrm{Cu}$ and $\mathrm{Pb}, 1000 \mathrm{mg} \mathrm{L}^{-1}$ ) were purchased from the General Research Institute for Nonferrous Metals (China). All used ultra-pure deionized water (DIW) of $18.2 \mathrm{M} \Omega-\mathrm{cm}$ in resistivity was produced by a Pall Cascada ${ }^{\mathrm{TM}}$ lab water purification system (Pall Corporation, USA). Different concentrations of nitric acid $\left(\mathrm{HNO}_{3}\right.$, Sinopharm Chemical Reagent Co., Ltd., China) and hydrochloric acid ( $\mathrm{HCl}$,
Sinopharm Chemical Reagent Co., Ltd., China) solution were prepared by diluting the concentrated $\mathrm{HNO}_{3}$ and concentrated $\mathrm{HCl}$ which were re-distilled through a sub-boiling distillation apparatus (BSB-939-IR, Berghof, Germany). The internal-fluorinated HDPE bottles (Nanjing Shuishan Plastic Products Co., Ltd., China) for storing the cleaning reagents $(\mathrm{NaOH}$ and $\mathrm{HCl})$, unfiltered and prefiltered water samples were first cleaned with $10 \%$ Decon $90^{\mathrm{TM}}$ detergent (Decon Laboratories Ltd., UK) and then sonicated sequentially in $1.5 \mathrm{~mol} \mathrm{~L}^{-1} \mathrm{HNO}_{3}, 1.2 \mathrm{~mol} \mathrm{~L}^{-1} \mathrm{HCl}$ and DIW for $3 \mathrm{~h}$, modified from the cleaning process in Li et al. (2015). All the used experimental labwares were also pre-cleaned following the same cleaning process, which were rinsed 3-5 times with DIW between each washing cycle and allowed to dry in a Class 100 clean bench. Finally, each dried bottle was double-packed and stored at $\sim 25^{\circ} \mathrm{C}$ for sampling. All experiments were performed in the Class 100 clean bench in the Yantai Institute of Coastal Zone Research, Chinese Academy of Sciences.

\subsection{Sample collection}

Surface samples (1 $\mathrm{m}$ deep), including riverine and estuary waters of two rivers, were collected in Yantai City, Eastern China, in January 2019 (Fig. 1). Six sampling sites, namely 1, 2, 3, 4, 5 and 6 , were on the verge of a rapidly developing aquaculture zone of China (Zhang et al., 2016). Surface water samples were collected using trace-metal-clean pole-sampling techniques that was equipped with a Teflon pole and attached to internal-fluorinated HDPE bottles at the end. After the water sample was collected, the sampling bottle was double bagged in polyethylene bags, and then stored in a sample box at $\sim{ }^{\circ} \mathrm{C}$ (Lu et al., 2019). The salinities of the 6 sampling sites (No. 1-6) were 29.6, 26.7, 0.5, 28.6, 24.0 and 0.3 , respectively, measured by using the SX713 Model salinometer from Shanghai San-Xin Instrumentation, Inc (Shanghai, China). Water samples were taken back to the laboratory and filtered (within 2 h) by using an enclosed filtration system, which was actually a pre-cleaned polysulfone vacuum filtration device (DS0320-5045, Nalgene ${ }^{\mathrm{TM}}$, Thermo Fisher Scientific Inc., USA) equipped with a perforated screw cap and a diaphragm vacuum pump (Tianjin Jinteng Experimental Equipment Co., Ltd., China). The unfiltered water samples were pumped along the C-flex ${ }^{\circledR}$ tubing (Cole-Parmer Inc., USA) into the upper part of the vacuum filtration device by a peristaltic pump (Masterflex ${ }^{\circledR}$ L/S, ColeParmer Inc., USA) while vacuum filtration was performed. Finally, pre-filtered samples were collected in another pre-cleaned $1 \mathrm{~L}$ internal-fluorinated HDPE bottles and then stored in freezer at $4{ }^{\circ} \mathrm{C}$ before further processing. The Supor ${ }^{\circledR}-2000.2 \mu \mathrm{m}$ membrane filters (Pall Corporation, USA) used in this work were pre-cleaned with $2 \% \mathrm{HNO}_{3}$ and then rinsed with DIW before use.

\subsection{CUF}

A fixed rotor centrifuge (Velocity 14R, Dynamica Corporation, Australia) was used with three kinds of CUF units (Macrosep ${ }^{\circledR}$, Pall Laboratory, USA) with respective cutoffs of $1 \mathrm{kDa}$ (MAP001C38), $3 \mathrm{kDa}$ (MAP003C36) and $10 \mathrm{kDa}$ (MAP010C38). Supplementary Material Fig. S1 shows a schematic diagram of the experiment process. Before CUF, the unit was thoroughly cleaned with a method modified from Guo et al. (2000) and Xu and Guo (2017), i.e. sequentially washed 5-10 times with $0.05 \mathrm{~mol} \mathrm{~L}^{-1} \mathrm{NaOH}$, $0.02 \mathrm{~mol} \mathrm{~L}^{-1} \mathrm{HCl}$ and DIW to remove possible contamination. The DIW blank was collected to check that the leaching of metals is not contributing to the concentration in samples. Then, the CUF unit was loaded with $15 \mathrm{~mL}$ of samples $(<0.2 \mu \mathrm{m})$, and centrifuged ( $4200 \times \mathrm{g}, 50-70 \mathrm{~min}$ ) to less than $0.5 \mathrm{~mL}$ at $4{ }^{\circ} \mathrm{C}$ constant temperature to separate the concentrates $(>1 \mathrm{kDa},>3 \mathrm{kDa}$ and $>10 \mathrm{kDa}$ ) for the determination of concentration of colloidal metals $(\mathrm{Cd}, \mathrm{Cu}$ 


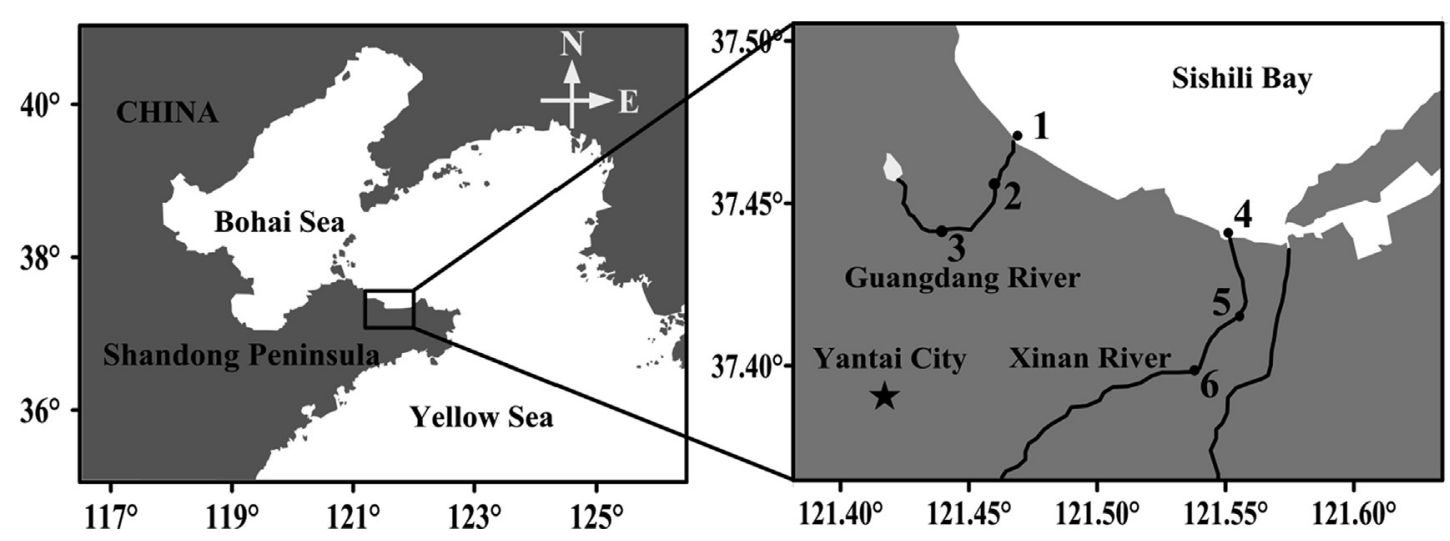

Fig. 1. Study area and sampling sites in the rivers and estuaries of Yantai City, China. The black dots indicate sampling sites.

and $\mathrm{Pb}$ ) with different molecular weights. Then, after CUF, $3 \% \mathrm{HNO}_{3}$ was added 3 times with $1 \mathrm{~mL}$ each time to the concentrate for extraction ( $\geq 1 \mathrm{~h}$ each time). Finally, three extracts were mixed and volume adjusted to $5 \mathrm{~mL}$ with $3 \% \mathrm{HNO}_{3}(\mathrm{v} / \mathrm{v})$. As for the ultrafiltrate, $0.2 \mathrm{~mL}$ was diluted to $10 \mathrm{~mL}$ with $3 \% \mathrm{HNO}_{3}(\mathrm{v} / \mathrm{v}) .<0.2 \mu \mathrm{m}$ total dissolved fraction was prepared by diluting $0.2 \mathrm{~mL}$ of prefiltered water sample to $10 \mathrm{~mL}$ with $3 \% \mathrm{HNO}_{3}$. All treated samples were stable at $25^{\circ} \mathrm{C}$ for $\geq 48 \mathrm{~h}$ and then measured using ICP-MS. Colloidal trace metal concentrations in different size ranges were calculated based on the difference in concentration between the initial sample and the ultrafiltrate samples (Xu et al., 2018). Based on this method, fractions can be defined as $<1 \mathrm{kDa}, 1-3 \mathrm{kDa}, 3-$ $10 \mathrm{kDa}$ and $10 \mathrm{kDa}-0.2 \mu \mathrm{m}$. In this way, a concentration factor (cf) of 3 was achieved for the colloids and of 0.02 for the ultrafiltrates (a 50 times dilution). After the whole experiment was completed, each CUF unit was recirculated, and then poured into sterile water and stored at $25^{\circ} \mathrm{C}$ in the dark.

\subsection{Membrane calibration}

To check the deviation of the MWCO of the ultrafiltration membrane used in this experiment from the manufacturer's cutoff ratings, we used standard macromolecules to calibrate the CUF unit, including vitamin $\mathrm{B}_{12}\left(\mathrm{VB}_{12}\right.$, Aladdin Industrial Corporation, Shanghai, China), with a nominal molecular weight (NMW) of $1.3 \mathrm{kDa}$, and standard fluorescent tagged dextrans (FTDs, TdB Consultancy AB, Uppsala, Sweden) with a NMW of 4.5, 9.5, 19.5 and $40 \mathrm{kDa}$, respectively.

Briefly, the standard macromolecules were added to the prefiltered seawater and thoroughly mixed (Supplementary Material Fig. S1), followed by CUF treatment. Then, the concentrations of the standard macromolecule in ultrafiltrate, concentrate and prefiltered sample were determined. For $\mathrm{VB}_{12}$, a standard curve method was used together with a TU-1810 UV-VIS spectrophotometer (Beijing Purkinje General Instrument Co., Ltd, China) following Jin et al. (2007). The standard curve and the corresponding linear information are shown in Supplementary Material Fig. S2a. The FTDs, as a polysaccharide, were measured using high performance liquid chromatography (HPLC). Samples were quantified on a Waters 515 HPLC equipped with a Waters 2414 refractive index detector (Waters Corporation, USA) and a Shodex OHpak SB-804 HQ size exclusion column $(10 \mu \mathrm{m}, 8.0 \times 30$ $0 \mathrm{~mm}$ ) using four standard curves (Supplementary Material Fig. S2b). Finally, the results were substituted into the following formula to calculate the retentions $(R)$ of five macromolecules, and the actual MWCOs of the CUF units were obtained:

$R=\left(1-\frac{C_{u}}{C_{i}}\right) \times 100 \%$
$C_{u}$ is the standard macromolecule concentration in the ultrafiltrate; $C_{i}$ is the initial standard macromolecule concentration on the ultrafilter. The actual MWCO is the molecular weight (approximate) that is $90 \%$ retained by the ultrafiltration membrane (Guo and Santschi, 2007; Xu and Guo, 2017). $R$ is the percentage reduction in $C_{i}$ on the ultrafilter.

\subsection{Metal analysis and data processing}

All water samples (after necessary processing) were measured using an inductively coupled plasma mass spectrometer (ICP-MS, ELAN DRC II, PerkinElmer ${ }^{\circledR}$, USA) fitted with nickel sampler cones and nickel skimmer cones, and an $8.7 \mathrm{nmol} \mathrm{L}^{-1}$ indium internal standard was spiked in every sample. Plasma generation for ICPMS analysis was operated with 99.999\% argon (Yantai Feiyuan Special Gas Co., Ltd., China) at the optimized plasma gas flow rate (GFR) of $15.0 \mathrm{~L} \mathrm{~min}^{-1}$, auxiliary GFR of $1.2 \mathrm{~L} \mathrm{~min}^{-1}$ and nebulizer GFR of $0.88 \mathrm{~L} \mathrm{~min}^{-1}$.

As for the method validation, blanks were estimated by performing ultrafiltration on DIW water followed $3 \% \mathrm{HNO}_{3}$ extraction, $3 \% \mathrm{HNO}_{3}$ dilution and ICP-MS parallel determination $(\mathrm{n}=11)$. The quantification limits (LOQ) for $\mathrm{Cd}, \mathrm{Cu}$ and $\mathrm{Pb}$ were 10 times of the standard deviation $(\sigma)$ of the blanks, and the detection limits (LOD) were $3 \sigma$. The corresponding results are shown in Table 1 along with the linear correlations $\left(R^{2}\right)$ and linear ranges of the method. The data presented reasonable linear ranges, associated with high $R^{2}$ and low LOD for each metal ensuring the method accuracy for subsequent experiments.

\section{Results and discussion}

\subsection{Centrifugal force and centrifugation time}

Ultrafiltration efficiency is affected by many factors, such as sample viscosity and initial volume, membrane pore size, centrifugation angle, centrifugal force and centrifugation time (Elsohaby et al., 2018; Loginov et al., 2017). Xu and Guo (2017) found that when the volume of the concentrate on the ultrafiltration membrane was $<500 \mu \mathrm{L}$ after CUF, the concentration ratio of the colloidal substance and the desalting efficiency of the seawater sample reached extremely high levels. In order to prevent sample overflow during centrifugation, an initial sample volume of $15 \mathrm{~mL}$ in the ultrafiltration unit was chosen. As two factors that directly affect the ultrafiltration efficiency, optimization of centrifugation time and centrifugal force is necessary. When the centrifugal force is constant, the ultrafiltration efficiency can be increased by prolonging the ultrafiltration time, however excessive time is likely to cause membrane rupture and shortens its service 
Table 1

Performance of the ICP-MS analysis method.

\begin{tabular}{|c|c|c|c|c|}
\hline Element & Linear ranges $\left(\mathrm{nmol} \mathrm{L}^{-1}\right)$ & Linear correlations $\left(R^{2}\right)$ & Detection limit $\left(\mathrm{nmol} \mathrm{L}^{-1}\right)$ & Quantification limit ( $\mathrm{nmol} \mathrm{L}^{-1}$ ) \\
\hline $\mathrm{Cd}$ & $0.2-89.0$ & 0.9999 & 0.022 & 0.073 \\
\hline $\mathrm{Cu}$ & $1.6-786.8$ & 0.9999 & 0.039 & 0.131 \\
\hline $\mathrm{Pb}$ & $0.2-120.7$ & 0.9999 & 0.005 & 0.015 \\
\hline
\end{tabular}

life (Sun et al., 2015). Therefore, the water sample (site 1) was used to investigate the effect of the centrifugal force $(1000,2000,3000$ and $4000 \times g)$ and the centrifugation time $(20,30,40,50,60$ and $70 \mathrm{~min}$ ) on the extraction efficiency. It should be noted that the volume of the concentrate was approximate because it could not be accurately measured. $10 \mu \mathrm{L}, 100 \mu \mathrm{L}, 1000 \mu \mathrm{L}$ and $5 \mathrm{~mL}$ pipettes were used for volume transfer and estimation during the experiment. By measuring the remaining volume of the concentrate, optimal conditions for each MWCO CUF units could be determined (Supplementary Material Fig. S3a-c)

As can be seen from Supplementary Material Fig. S3a-c, the concentrates in the three CUF units reached a minimum volume under test conditions of NO. $24(4000 \times \mathrm{g}, 70 \mathrm{~min})$, with volumes of $\sim 450$ (1 kDa), 300 (3 kDa) and $\sim 310 \mu \mathrm{L}$ (10 kDa), respectively. However, the experimental conditions satisfying the experimental requirements of the concentrate volume of $<500 \mu \mathrm{L}$ were quite numerous. For example, a $3 \mathrm{kDa}$ ultrafiltration centrifuge unit could concentrate the sample to $<500 \mu \mathrm{L}$ in NO. $18(3000 \times \mathrm{g}, 70 \mathrm{~min}), 22$ $(4000 \times \mathrm{g}, 50 \mathrm{~min}), 23(4000 \times \mathrm{g}, 60 \mathrm{~min})$ and $24(4000 \times \mathrm{g}, 70 \mathrm{~min})$, $10 \mathrm{kDa}$ could reach the requirements in both NO. $22(4000 \times \mathrm{g}$, $50 \mathrm{~min}), 23(4000 \times \mathrm{g}, 60 \mathrm{~min})$ and $24(4000 \times \mathrm{g}, 70 \mathrm{~min})$. Therefore, in order to meet both the centrifugal effect and the shortest experimental time, the $1 \mathrm{kDa}$ unit was used under the NO. 24 condition $(4000 \times \mathrm{g}, 70 \mathrm{~min})$ and the 3 and 10 units were used under the condition of NO. $22(4000 \times \mathrm{g}, 50 \mathrm{~min})$.

As matrix effects can alter the centrifugation efficiency from one sample to another, the optimal ultrafiltration parameters calibrated for sample 1 were tested on the five remaining samples (Supplementary Material Fig. S3d). As sample 3 (riverine water) final $1 \mathrm{kDa}$ concentrate volume was nearly $500 \mu \mathrm{L}$ the centrifugal force was increased from $4000 \times g$ to $4200 \times g$. The optimal experimental conditions we chose were consequent as follows: a centrifugal force of $4200 \times g$ and centrifugation time of 70 ( $1 \mathrm{kDa}), 50$ (3 $\mathrm{kDa})$ and $50 \mathrm{~min}(10 \mathrm{kDa})$, respectively.

\subsection{Extraction method}

In order to investigate the ability of ultrapure water and different concentrations of $\mathrm{HNO}_{3}$ to extract colloidal $\mathrm{Cd}, \mathrm{Cu}$ and $\mathrm{Pb}$ trapped on the membrane, sample 1 was selected and centrifuged ultrafiltration according to the method described in Section 2.3. 6 different $\mathrm{HNO}_{3}$ concentrations $(0.0,0.5,1.0,1.5,2.0$ and 3.0\%, v/ v) were tested to assess the efficiency of $\mathrm{Cd}, \mathrm{Cu}$ and $\mathrm{Pb}$ extraction from concentrated colloids prior to the $3 \% \mathrm{HNO}_{3} 5 \mathrm{~mL}$ dilution step. In addition, $0.2 \mathrm{~mL}$ of ultrafiltrate was aspirated and the same extract was used to dilute it to $10 \mathrm{~mL}$. All samples were measured using ICP-MS and the results of recovery (or extraction rate) are shown in Fig. 2.

The results showed that the recoveries of colloidal $\mathrm{Cd}, \mathrm{Cu}$ and $\mathrm{Pb}$ in the DIW extracts of the three ultrafiltration centrifuge units were lower, only 20.7-70.9\%. However, when the concentration of $\mathrm{HNO}_{3}$ was higher than $1.5 \%$, the recoveries of $\mathrm{Cd}, \mathrm{Cu}$ and $\mathrm{Pb}$ measured in different concentrations of $\mathrm{HNO}_{3}$ extract were close and stable, both higher than $90.3 \%$. This indicates that the method blanks were low and the target metals could be efficiently extracted by a higher concentration $(\geq 1.5 \%)$ of $\mathrm{HNO}_{3}$ solution. Since the dilution of the standard solution and the working curve was $3 \% \mathrm{HNO}_{3}$ in the ICP-MS measurement, $3 \% \mathrm{HNO}_{3}$ was selected as the acidified extract.

\subsection{Actual molecular weight cutoff (MWCO) of ultrafiltration membrane}

It should be noted that the manufacturer-rated MWCOs of CUF units may be different from the actual MWCOs (Guo et al., 2000; $\mathrm{Xu}$ and Guo, 2017). Therefore, after the calibration process described in Section 2.4, the actual MWCOs of the used CUF units and their retentions $(R)$ were evaluated. Retention characteristics of different standard macromolecules by CUF units are shown in Supplementary Material Fig. S4.

As depicted in Supplementary Material Fig. S4, for the $1 \mathrm{kDa}$ unit, $R$ of $\mathrm{VB}_{12}$ was about $1.3 \%$, which indicated that the manufacturer rated MWCO was much lower than the actual MWCO of the ultrafiltration membrane. As for $3 \mathrm{kDa}$ unit, $R$ was $\sim 83.1 \%$ for the $4.5 \mathrm{kDa}$ FTD although it reached $93.4 \%$ for the $9.5 \mathrm{kDa}$ FTD. The $10 \mathrm{kDa}$ unit was no exception; $R$ was $\sim 77.6 \%$ for the $19.5 \mathrm{kDa}$ FTD although it reached $93.3 \%$ for the $40 \mathrm{kDa}$ FTD. The corresponding molecular weight based on the $90 \% R$ was taken as the actual MWCO of the ultrafiltration membrane (Guo and Santschi, 2007), and its value was 4.9, 8.5 and $33.9 \mathrm{kDa}$ for the manufacturer rated 1,3 , and $10 \mathrm{kDa}$ membranes, respectively, which were comparable to the corresponding values of $2.5,7.4$ and $32 \mathrm{kDa}$ gained through the same method by Xu and Guo (2017).

Yet, since the curve in Supplementary Material Fig. S4 was a fitting curve, the results obtained from the figure may be different from the true value. For example, the retention of a $1 \mathrm{kDa}$ ultrafiltration membrane for a 4.5 kDa FTD was 97.1\% (see Supplementary Material Fig. S4), which indicated that the actual MWCO of $1 \mathrm{kDa}$ ultrafiltration membrane should be less than $4.5 \mathrm{kDa}$, but the value from the graph was $4.9 \mathrm{kDa}$. However, it was undeniable that the ultrafiltration performance of the ultrafiltration membrane could still be better evaluated by the above necessary calibration experiments. Besides, the results of the calibration indicated that the rated MWCOs significantly overestimated the colloidal trace element concentration in ultrafiltrate.

The results of this study further confirmed the conclusion made in Xu and Guo (2017) that the actual MWCO for the 1, 3, and $10 \mathrm{kDa}$ CUF units were estimated to be $>2,>7$, and $>32 \mathrm{kDa}$, respectively, and the MWCO was not necessarily the same even with the different batches of CUF units produced by the same manufacturer.

\subsection{Mass balance}

The mass balance directly determines the quality of the analytical test results (Liu and Lead, 2006; Liu et al., 2007). In this study, sample 1 was selected as the study object and mass balance was performed by adding known concentrations of metal standard solutions to the filtered seawater sample $(<0.2 \mu \mathrm{m})$. Then, by using the CUF method described in Section 2.3, the samples were separated according to different molecular weight ranges $(<1 \mathrm{kDa}, 1-$ $3 \mathrm{kDa}, 3-10 \mathrm{kDa}$ and $10 \mathrm{kDa}-0.2 \mu \mathrm{m})$, and then $3 \% \mathrm{HNO}_{3}$ was used for extraction and dilution. Spiked total dissolved fraction $(<0.2 \mu \mathrm{m})$ was prepared using the same dilution method (a 50 times dilution). After being respectively processed by CUFs with 

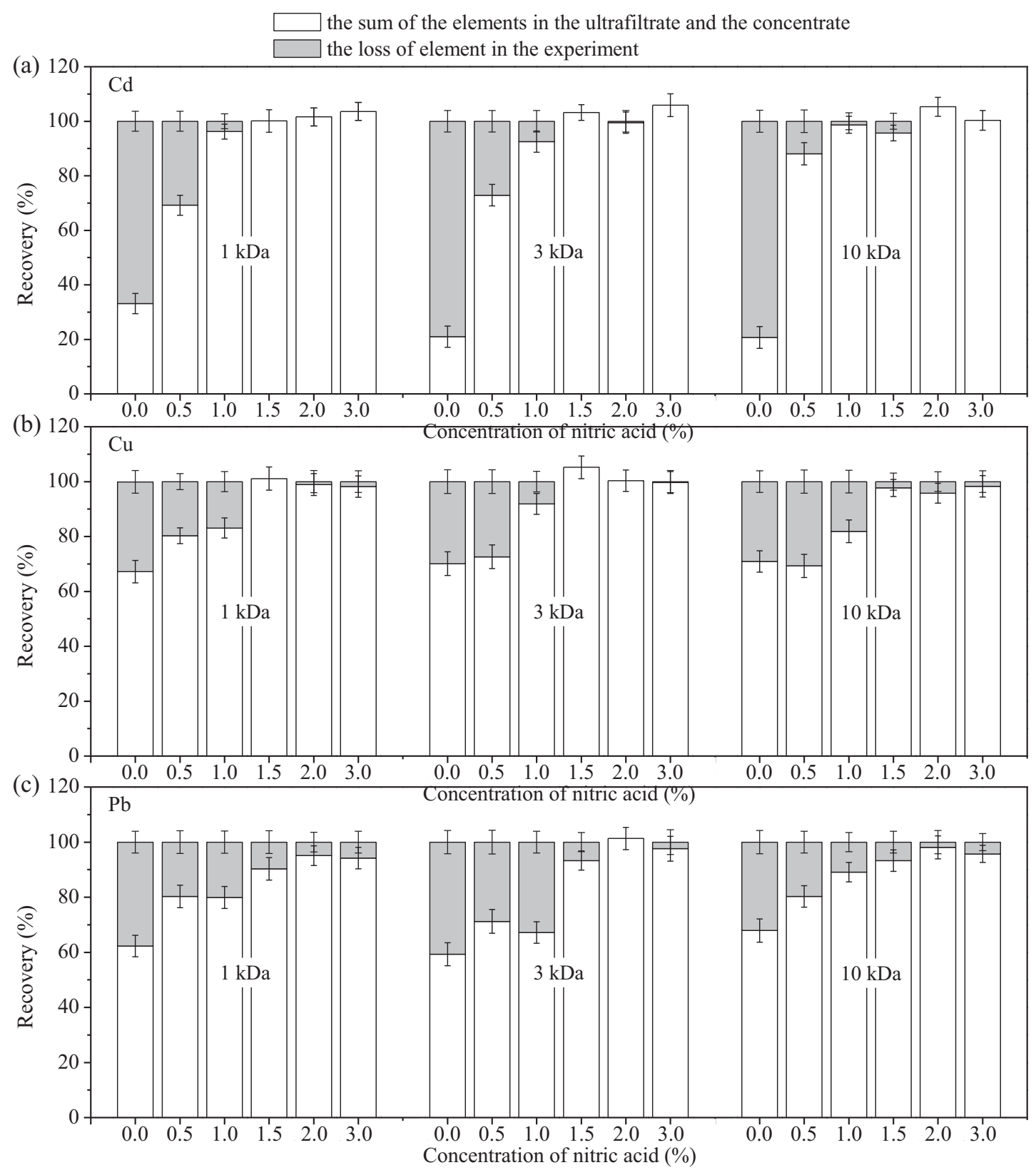

Fig. 2. Recoveries of $\mathrm{Cd}, \mathrm{Cu}$ and $\mathrm{Pb}$ extraction in different extract concentrations.

1, 3 and $10 \mathrm{kDa}$ MWCOs and the other necessary pre-processing, the concentrations of the three target metals were obtained by 3 parallel determinations of ICP-MS under the optimal conditions. The recoveries (mass balance) of three metals were obtained and calculated by the following form (Liu et al., 2013):

Recovery $=\frac{C_{c} V_{c}+C_{u} V_{u}}{C_{t} V_{t}} \times 100 \%$

$C$ : metal concentration; $V$ : volume; $c, u$ and $t$ : concentrate, ultrafiltrate and total dissolved phase $(<0.2 \mu \mathrm{m})$. If the recovery is $<100 \%$, the target element is lost during CUF; if the recovery is $>100 \%$, it indicates that the target element is contaminated during CUF. The corresponding results are shown in Fig. 3.

The results showed that the recoveries of the three CUF units at different spike levels were $85.3-100.8 \%$, which proved that the developed method could be used to determine the three colloidal metals in the actual water samples. At the same time, a thorough pre-cleaning process is indispensable and necessary for improving the accuracy of the experiment and the efficiency of the entire CUF system (Guo and Santschi, 2007).

\subsection{Contrast with other methods}

Although the separation and determination of colloidal trace metals in seawater has become no longer complicated, the diversity of available colloids separation techniques and their operational characteristics leads to a lack of standardized methods within the community (Wen et al., 1996; Liu et al., 2013; Hargreaves et al., 2017). The method described in this study was compared with other approaches in literature (Table 2).

Wen et al. (1996) proposed a method for the collection of colloidal material for trace metal phase speciation studies in marine environments. The pre-cleaning time of the cross-flow ultrafiltration (CFUF) system was $>1.5 \mathrm{~h}$, and the $c f$ was $5-10$. Liu et al. 


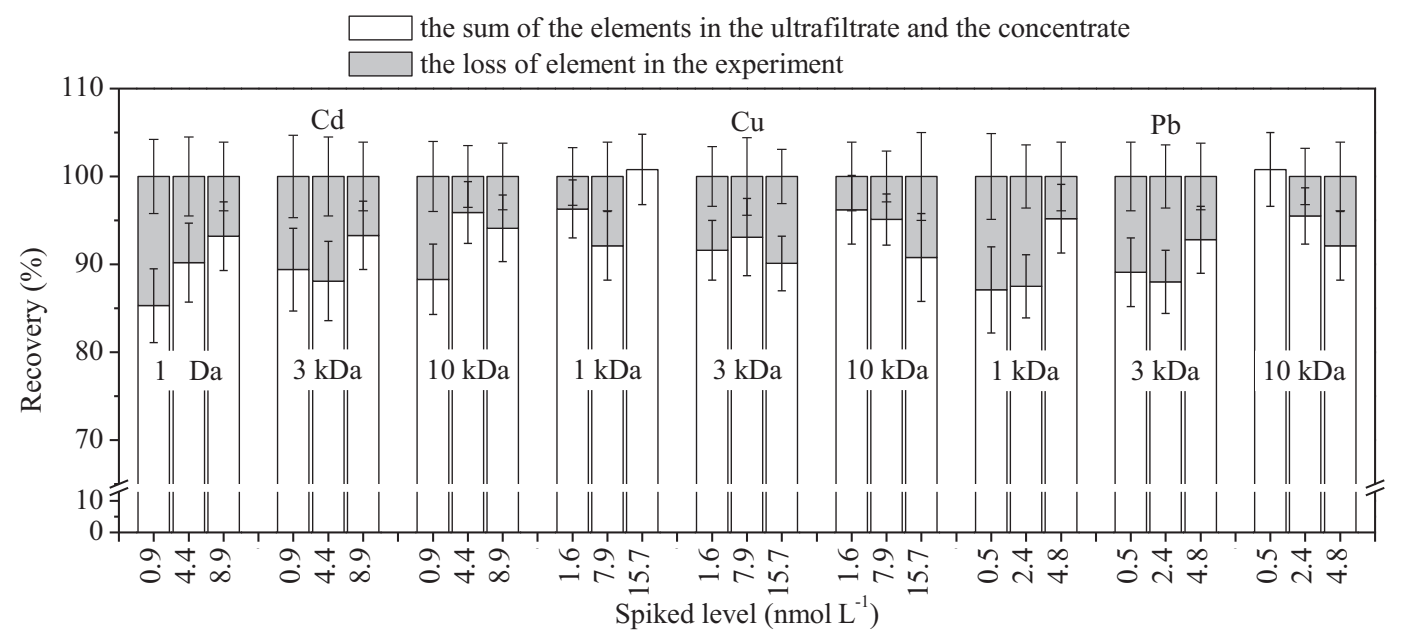

Fig. 3. The mass recovery of $\mathrm{Cd}, \mathrm{Cu}$ and $\mathrm{Pb}$ in different MWCO of CUF units.

Table 2

Analytical performance information in different research.

\begin{tabular}{|c|c|c|c|c|c|}
\hline Sample & Separation method & Instrument & Cleaning time & $c f^{\mathrm{a}}$ & Reference \\
\hline Riverine and estuarine water & CUF & ICP-MS & $\sim 1 \mathrm{~h}$ & $>30$ & This study \\
\hline Lake and seawater & CFUF & GFAAS $^{b}$ & $>1.5 \mathrm{~h}$ & $5-10$ & Wen et al. (1996) \\
\hline Freshwater & CFUF & $\mathrm{IC}^{\mathrm{C}}$ & $>4 \mathrm{~h}$ & $\geq 17$ & Liu et al. (2013) \\
\hline Wastewater & Filtration & ICP-MS & $-{ }^{d}$ & 1.4 & Hargreaves et al. (2017) \\
\hline
\end{tabular}

${ }^{\text {a }} c f$ in the table is the data before dilution.

b "GFAAS" represents graphite furnace atomic absorption spectrometer.

c "IC" represents ion chromatograph.

d “_" represents no relevant reference data.

(2013) used CFUF and diffusive gradients (DGT) in thin films with open-pore gel (OP) and restricted pore (RP) to measure trace metal speciation in selected UK freshwaters. Although the $c f$ of the method exceeded 17, the cleaning time was about $4 \mathrm{~h}$ to ensure the accuracy of the results. Hargreaves et al. (2017) used the regenerated cellulose filter to separate the colloidal metal in UK wastewater, but the maximum of was only 1.4 .

In this study, only $15 \mathrm{~mL}$ sample was required for single ultrafiltration, the extraction time of the sample was $\leq 70 \mathrm{~min}$, and multiple samples $(2-3)$ could be performed simultaneously. In addition, the amount of reagents consumed by the necessary cleaning process was also very small (60-120 mL per CUF unit), and the operation was simple. In contrast, the ultrafiltration column used has a long pre-cleaning time, and the used reagent volume was large (500-1000 $\mathrm{mL}$ once), and the $c f$ was unstable (Pokrovsky et al., 2012; Liu et al., 2013). What's more, the time taken to separate the sample would become significantly longer as the sample volume becomes larger. On the contrary, the modified method was easy to control, had lower cost and better effect. However, the advantage of the CFUF method was that the obtained colloid was bulky (usually measured in liters) (Liu et al., 2013). This means that a large amount of colloidal samples could be obtained by separating once so that substances such as colloidal organic carbon and colloidal organic nitrogen could be more comprehensively detected, and more information could be obtained (Guo and Santschi, 2007). In contrast, the volume of the sample obtained by CUF at one time was usually less than $1 \mathrm{~mL}$ (Xu and Guo, 2017). If a large amount of substances were to be detected, the volume of $1 \mathrm{~mL}$ was obviously insufficient, and multiple parallel experiments were required. In summary, the method used in this work was an efficient and low-cost method for extracting colloidal metals in the aquatic system.

\subsection{Method application}

In this study, the surface waters of 6 sites in Yantai City (sites 16 in Fig. 1) were collected, and the concentrations of studied metals were analyzed by the proposed method to evaluate the applicability. The results of the colloidal trace metal concentrations and percentages for each molecular weight are shown in Figs. 4 and 5, respectively. For the sake of comparison, concentrations and percentages of studied metals in collected samples and other aquatic systems are shown in Table 3.

In terms of concentrations (Fig. 4), the results showed that the $<1 \mathrm{kDa}$ fraction of $\mathrm{Cd}, \mathrm{Cu}$ and $\mathrm{Pb}$ in the Guangdang River (sites 1, 2 and 3) were $0.12-0.24,1.13-30.93$ and $1.52-1.65 \mathrm{nmol} \mathrm{L}^{-1}$, respectively, the $1-3 \mathrm{kDa}$ fraction of $\mathrm{Cd}, \mathrm{Cu}$ and $\mathrm{Pb}$ were $0.007-$ $0.01,0.24-2.03$ and $0.06-0.34 \mathrm{nmol} \mathrm{L}^{-1}$, respectively, the 310 kDa fraction of $\mathrm{Cd}, \mathrm{Cu}$ and $\mathrm{Pb}$ were $0.0006-0.01,0.03-2.32$ and $0.02-0.31 \mathrm{nmol} \mathrm{L}^{-1}$, respectively, and the $10 \mathrm{kDa}-0.2 \mu \mathrm{m}$ fraction of $\mathrm{Cd}, \mathrm{Cu}$ and $\mathrm{Pb}$ were $0.01-0.02,0.08-2.54$ and $0.16-$ $0.56 \mathrm{nmol} \mathrm{L}^{-1}$, respectively; in the Xin'an River (sites 4,5 and 6), the concentrations of $\mathrm{Cd}, \mathrm{Cu}$ and $\mathrm{Pb}$ were $0.14-0.23,0.81-22.09$ and 1.21-2.53 $\mathrm{nmol} \mathrm{L}^{-1}$ in the $<1 \mathrm{kDa}$ fraction, 0.001-0.02, 0.122.37 and $0.02-0.05 \mathrm{nmol} \mathrm{L}^{-1}$ in the $1-3 \mathrm{kDa}$ fraction, 0.003-0.01, $0.06-1.68$ and $0.01-0.02 \mathrm{nmol} \mathrm{L}^{-1}$ in the $3-10 \mathrm{kDa}$ fraction, and $0.01-0.02,0.06-2.30$ and $0.20-0.26 \mathrm{nmol} \mathrm{L}^{-1}$ in the $10 \mathrm{kDa}-0.2 \mu$ $\mathrm{m}$ fraction. Obviously, the concentrations of the three metals in each fraction significantly increased along the river, which could be attributed to a release from sediments during the estuarine mixing (Santos-Echeandia et al., 2008). However, under similar sampling conditions, the concentrations of the three metals in the two rivers in each fraction were not exactly the same, especially $\mathrm{Pb}$, showing the most obvious difference (Fig. 4e and $\mathrm{f}$ ). Meanwhile, the geographical proximity of the two rivers did not 

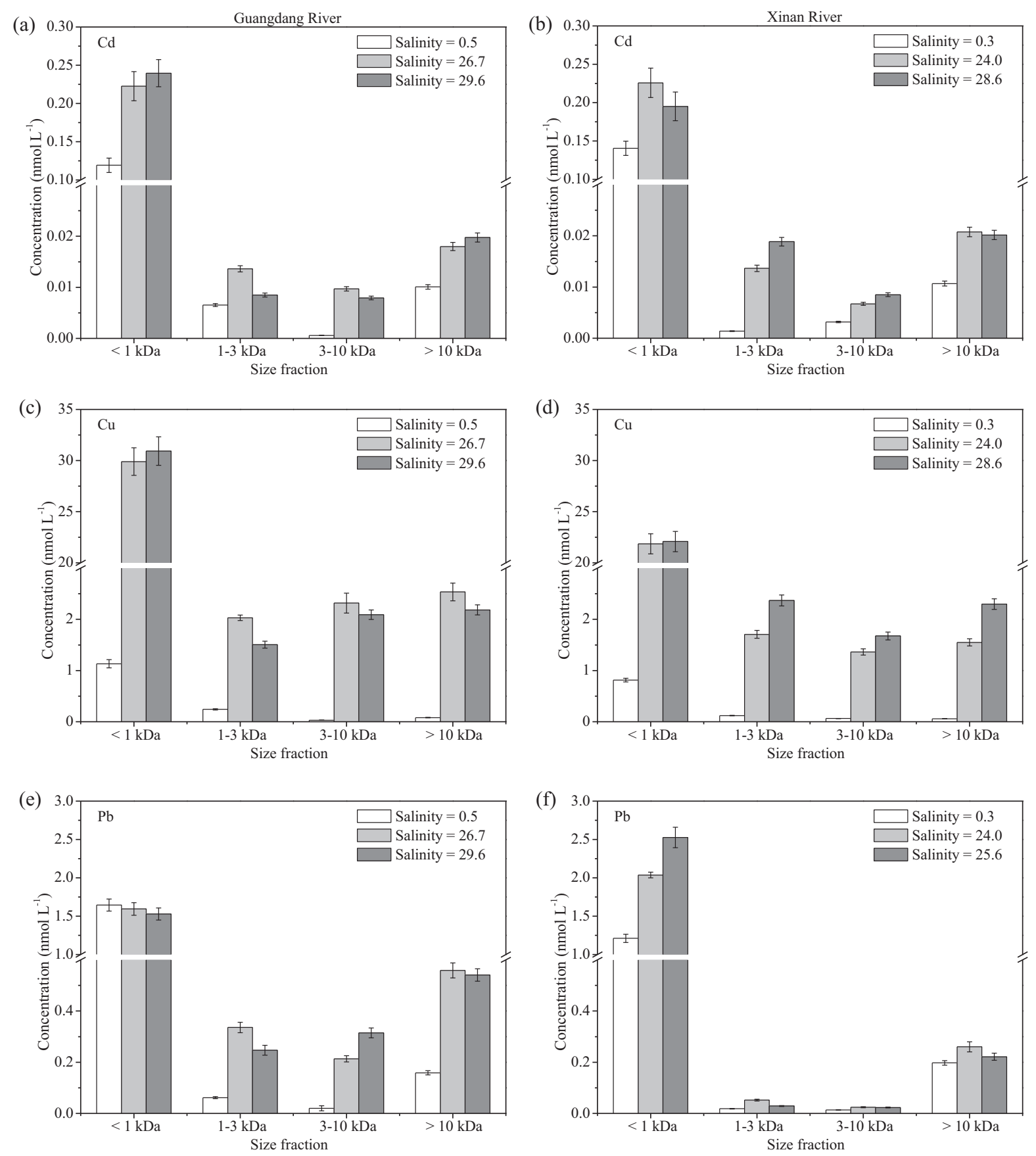

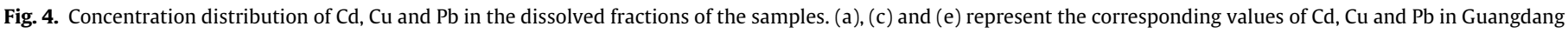
River, respectively, and (b), (d) and (f) represent the corresponding values of $\mathrm{Cd}, \mathrm{Cu}$ and $\mathrm{Pb}$ in Xin'an River, respectively.

produce the expected similar results. On the contrary, in the LMW colloids (1-10 kDa), Pb showed significant differences in the two rivers, which was mainly attributable to the physical and chemical characteristics. We compared the results with other published data (Table 3) and found that the concentrations of colloidal Cd in the two studied rivers were close to that of the Venice Lagoon (0.0001-0.04 $\mathrm{nmol} \mathrm{L}^{-1}$ ) (Martin and Dai, 1995), but significantly lower than that of the Penzé estuary (0.07-0.30 nmol L ${ }^{-1}$ ) (Waeles et al., 2008); the concentrations of colloidal Cu were similar to that of the Venice Lagoon (1.89-8.34 $\left.\mathrm{nmol} \mathrm{L}^{-1}\right)$, but higher than that of the Penzé estuary $\left(0.13-0.27 \mathrm{nmol} \mathrm{L}^{-1}\right)$; colloidal $\mathrm{Pb}$, due to the obvious difference in colloidal concentration between the two rivers, was at a lower colloidal concentration level in the
Xin'an River, which was close to the Penzé estuary (0.03-0.27 nmol $\left.\mathrm{L}^{-1}\right)$, and the concentrations in the Guangdang River were higher than that of the Venice Lagoon (0.002-0.97 $\mathrm{nmol} \mathrm{L}^{-1}$ ).

As for the percentages (Fig. 5), truly dissolved $\mathrm{Cd}, \mathrm{Cu}$ and $\mathrm{Pb}(<1$ $\mathrm{kDa}$ ) in the Guangdang River were $83-87 \%, 76-84 \%$ and $58-87 \%$ of their respective total dissolved pools $(<0.2 \mu \mathrm{m})$, respectively, the $1-3 \mathrm{kDa}$ fraction of three metals were $3-5 \%, 4-16 \%$ and $3-12 \%$, respectively, the $3-10 \mathrm{kDa}$ fractions were $0.4-4 \%, 2-6 \%$ and $1-$ $12 \%$, respectively, and the $10 \mathrm{kDa}-0.2 \mu \mathrm{m}$ fractions were $\sim 7 \%, 5-$ $7 \%$ and $8-14 \%$, respectively; in the Xin'an River, the corresponding values of $\mathrm{Cd}$ in the four fractions (i.e. $<1 \mathrm{kDa}, 1-3 \mathrm{kDa}, 3-10 \mathrm{kDa}$ and $10 \mathrm{kDa}-0.2 \mu \mathrm{m}$ ) were $80-90 \%, 1-8 \%, 2-4 \%$ and $7-8 \%$, respectively, the percentages of $\mathrm{Cu}$ in the four fractions were $77-83 \%$, 

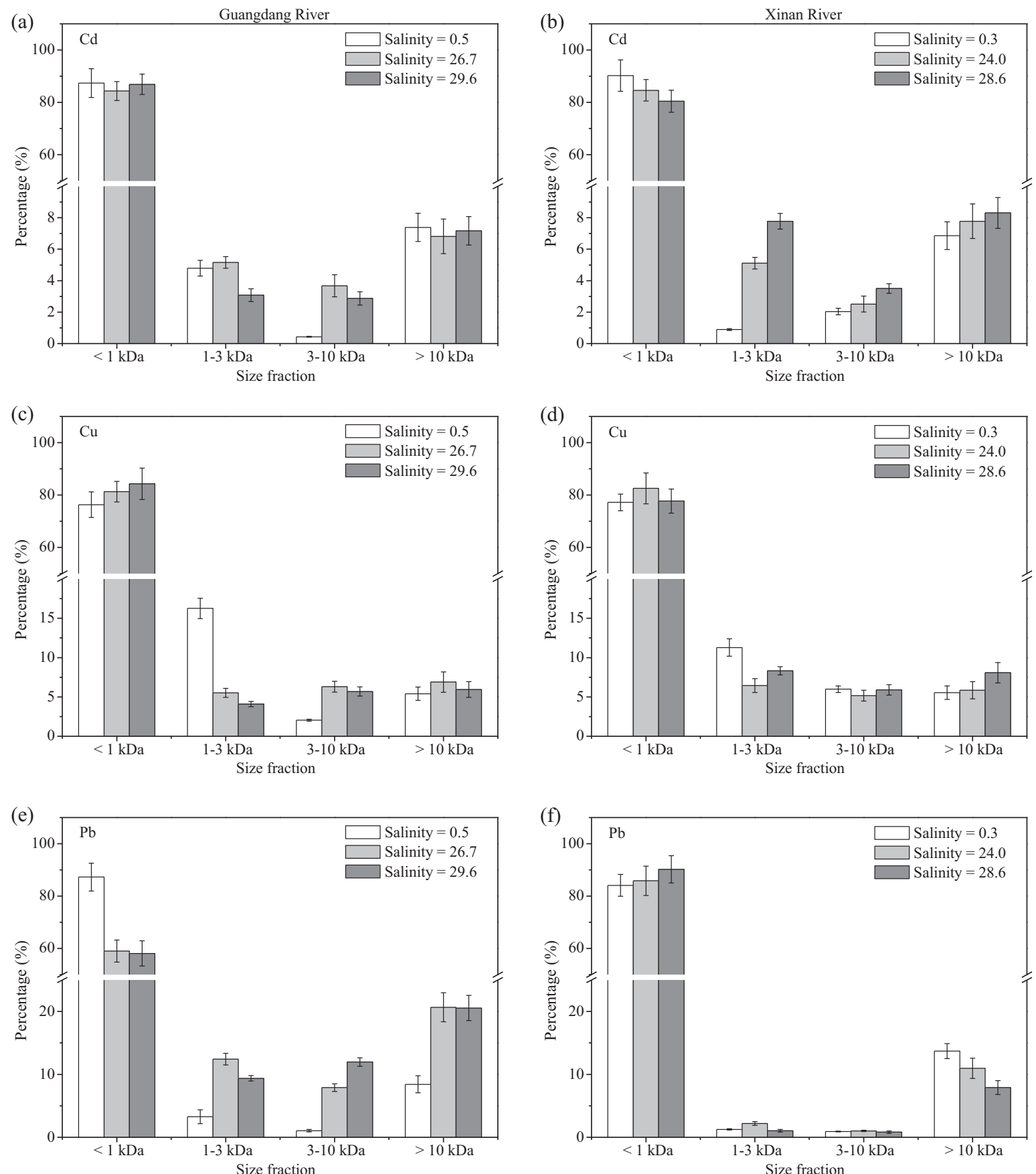

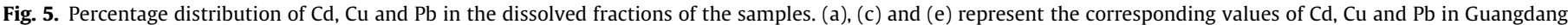
River, respectively, and (b), (d) and (f) represent the corresponding values of $\mathrm{Cd}, \mathrm{Cu}$ and $\mathrm{Pb}$ in Xin'an River, respectively.

Table 3

A comparison of the data in this study and the other literature. $C_{T}$ and $C_{C}$ represent the concentrations of truly dissolved phase and colloidal phase, respectively.

\begin{tabular}{|c|c|c|c|c|c|c|c|c|c|c|c|c|c|}
\hline \multirow[t]{2}{*}{ Location } & \multirow{2}{*}{$\begin{array}{l}\text { Prefilter } \\
(\mu \mathrm{m})\end{array}$} & \multirow{2}{*}{$\begin{array}{l}\text { Membrane's } \\
\text { cutoff (kDa) }\end{array}$} & \multirow[t]{2}{*}{$c f$} & \multicolumn{3}{|c|}{$C_{T}\left(\mathrm{nmol} \mathrm{L}^{-1}\right)$} & \multicolumn{3}{|c|}{$C_{C}\left(\mathrm{nmol} \mathrm{L}^{-1}\right)$} & \multicolumn{3}{|c|}{$C_{C} /\left(C_{T}+C_{C}\right)(\%)$} & \multirow[t]{2}{*}{ Reference } \\
\hline & & & & $\mathrm{Cd}$ & $\mathrm{Cu}$ & $\mathrm{Pb}$ & $\mathrm{Cd}$ & $\mathrm{Cu}$ & $\mathrm{Pb}$ & $\mathrm{Cd}$ & $\mathrm{Cu}$ & $\mathrm{Pb}$ & \\
\hline $\begin{array}{c}\text { Guangdang } \\
\text { River }\end{array}$ & 0.2 & 1,3 and 10 & $>30$ & $\begin{array}{l}0.12- \\
0.24\end{array}$ & $\begin{array}{l}1.13- \\
30.93\end{array}$ & $\begin{array}{l}1.52- \\
1.65\end{array}$ & $\begin{array}{l}0.02- \\
0.04\end{array}$ & $\begin{array}{l}0.35- \\
6.88\end{array}$ & $\begin{array}{l}0.24- \\
1.11\end{array}$ & $\begin{array}{l}13- \\
17\end{array}$ & $\begin{array}{l}16- \\
24\end{array}$ & $\begin{array}{l}13- \\
42\end{array}$ & This study \\
\hline Xin'an River & 0.2 & 1,3 and 10 & $>30$ & $\begin{array}{l}0.14- \\
0.23\end{array}$ & $\begin{array}{l}0.81- \\
22.09\end{array}$ & $\begin{array}{l}1.21- \\
2.53\end{array}$ & $\begin{array}{l}0.02- \\
0.05\end{array}$ & $\begin{array}{l}0.24- \\
6.34\end{array}$ & $\begin{array}{l}0.23- \\
0.34\end{array}$ & $\begin{array}{l}10- \\
20\end{array}$ & $\begin{array}{l}17- \\
23\end{array}$ & $\begin{array}{l}10- \\
16\end{array}$ & This study \\
\hline $\begin{array}{l}\text { Venice Lagoon, } \\
\text { Italy }\end{array}$ & 0.4 & $10^{\mathrm{a}}$ & $\sim 1.1$ & $\begin{array}{l}0.007- \\
0.083\end{array}$ & $\begin{array}{l}3.15- \\
8.85\end{array}$ & $\begin{array}{l}0.02- \\
0.16\end{array}$ & $\begin{array}{l}0.001- \\
0.043\end{array}$ & $\begin{array}{l}1.18- \\
8.34\end{array}$ & $\begin{array}{l}0.002- \\
0.98\end{array}$ & 34 & 41 & 58 & $\begin{array}{l}\text { Martin and Dai } \\
\text { (1995) }\end{array}$ \\
\hline $\begin{array}{l}\text { Penzé estuary, } \\
\text { France }\end{array}$ & $\begin{array}{l}0.2 \text { and } \\
0.45\end{array}$ & $\begin{array}{l}5,10,30,50 \text { and } \\
300\end{array}$ & $\begin{array}{l}3- \\
13\end{array}$ & $\begin{array}{l}0.01- \\
0.07\end{array}$ & $\begin{array}{l}0.13- \\
0.27\end{array}$ & $\begin{array}{l}0.003- \\
0.03\end{array}$ & $\begin{array}{l}0.07- \\
0.30\end{array}$ & $\begin{array}{l}2.14- \\
2.86\end{array}$ & $\begin{array}{l}0.03- \\
0.27\end{array}$ & 82 & 94 & 91 & $\begin{array}{l}\text { Waeles et al. } \\
(2008)\end{array}$ \\
\hline
\end{tabular}

a $10 \mathrm{kDa}$ was used as the boundary between truly dissolved and colloidal phases in that study. 
$7-11 \%, 5-6 \%$ and $6-8 \%$, respectively, and the percentages of $\mathrm{Pb}$ in the four fractions were $84-90 \%, 1-2 \%, \sim 1 \%$ and $8-14 \%$, respectively. For colloidal $\mathrm{Cd}$ (Fig. 5a and b) and colloidal $\mathrm{Pb}$ (Fig. 5e and f), the percentages of $10 \mathrm{kDa}-0.2 \mu \mathrm{m}$ fraction were higher than the $1-$ $3 \mathrm{kDa}$ fraction and the 3-10 kDa fraction, indicating that the colloidal material in this size range may dominate the forms of $\mathrm{Cd}$ and $\mathrm{Pb}$ in the colloidal phase. As for $\mathrm{Cu}$, the 1-3 $\mathrm{kDa}$ fraction was clearly the dominant one (Fig. $5 \mathrm{c}$ and d). However, the studies by Dai and Martin (1995) in the Ob estuary and Waeles et al. (2008) in the Penzé estuary have shown that most of the colloidal $\mathrm{Cu}$ was present in the $10 \mathrm{kDa}-0.2 \mu \mathrm{m}$ fraction of the organic matter, and colloidal $\mathrm{Cd}$ and $\mathrm{Pb}$ may be more likely to combine with the LMW colloids (1-10 kDa), which are the opposite to the results we got. These obvious differences should thus be attributed to the properties of the colloidal material in the study areas. From the comparative data in Table 3, it can be seen that the percentages of colloidal $\mathrm{Cd}$ and $\mathrm{Cu}$ of their respective total dissolved concentrations in the study area were lower than that of the Venice Lagoon (34\% Cd and 42\% Cu) (Martin and Dai, 1995) and the Penzé estuary ( $82 \% \mathrm{Cd}$ and $94 \% \mathrm{Cu}$ ) (Waeles et al., 2008). Only the percentages of colloidal $\mathrm{Pb}$ in the estuary area were close to $42 \%$, but still lower than the Venice Lagoon (58\%) (Martin and Dai, 1995) and the Penzé estuary (91\%) (Waeles et al., 2008).

\subsection{Size distribution variations of colloidal metals along the salinity}

\subsection{1. $C d$}

Previous studies have shown that changes in the concentration of chloride ions $\left(\mathrm{Cl}^{-}\right)$have a significant effect on the dynamic of some metals in the aquatic system (Byrne and Yao, 2000; Colombo et al., 2008). Fig. 4a and b show the distinct characteristics of various $\mathrm{Cd}$ concentrations increasing with salinity gradient, indicating that all of the four fractions were enriched during the river-sea mixing process (Waeles et al., 2008). However, as shown in Fig. $5 \mathrm{a}$ and b, $10 \mathrm{kDa}-0.2 \mu \mathrm{m}$ Cd was always at a relatively stable level ( $8 \%$ ), whereas the $1-10 \mathrm{kDa} C d$ was opposite (2.9-11.3\%). For example, in the Xin'an River, 1-3 kDa Cd was constantly increasing with salinity gradient, and the percentage of variation varied widely (from $0.9 \%$ to $7.8 \%$ ) and larger than that of the other two colloidal fractions (3-10 kDa and $10 \mathrm{kDa}-0.2 \mu \mathrm{m}$ ), indicating that this fraction may dominate the migration of $\mathrm{Cd}$ in this region. In the Guangdang river, 3-10 kDa fraction may have similar characteristics $(0.48-3.7 \%)$.

However, in the Guangdang River, both 1-3 kDa and 3-10 kDa fraction showed significant downward trend accompanied by a change in salinity from 26.7 to 29.6 (Fig. 5a), indicating that the coagulation/flocculation of colloidal organic matter in this region was considerable, which was generally thought to occur in macromolecular colloidal matter (Tang et al., 2001). Typically, 1-10 kDa organics are primarily considered to be humic/fulvic compounds or peptides (newly released, such as polypeptides) (Kawakami et al., 2006; Lead and Wilkinson, 2006). In the Xin'an River (Fig. 5b), the apparent enrichment of $1-10 \mathrm{kDa} C d$ could be attributed to the change of $\mathrm{Cd}$ from particle-desorbed phase to stable organicCd complex (Kozelka and Bruland, 1998; Wells et al., 1998), and the contribution of organic matter to the formation of colloidal Cd was particularly important in winter (Waeles et al., 2005). According to Gerringa et al. (1996), the source of these organics (1-10 kDa) may be derived from the degradation of particulate organic matter or the particle desorption.

\subsection{2. $\mathrm{Cu}$}

Obviously, compared with the estuary area, 1-3 kDa colloidal $\mathrm{Cu}$ in both rivers showed a decreasing trend (Fig. 5c and d) in the lower salinity zone (from $\sim 0.3$ to $\sim 27$ ), while the addition occurred in the 3-10 kDa fraction (Guangdang River) and
$10 \mathrm{kDa}-0.2 \mu \mathrm{m}$ fraction (Xin'an River). This indicates that the flocculation process of LMW colloid in this area promotes the migration of the colloidal $\mathrm{Cu}$ to the high-molecular-weight form. However, in the Guangdang estuary, $\mathrm{Cu}$ in three colloidal fractions (1-3 kDa, 3-10 kDa and $10 \mathrm{kDa}-0.2 \mu \mathrm{m}$ ) showed a removal behavior, which may be attributed to the reduction of strong Cu-ligands in this area (Tang et al., 2001). In addition, colloidal flocculation may be the main cause of $\mathrm{Cu}$ removal in studies of several estuaries (Apte et al., 1990; Waeles et al., 2008), but this is generally thought to occur in macromolecular colloids ( $10 \mathrm{kDa}-0.2 \mu \mathrm{m}$ ), which are mainly considered to be newly released intra-cellular biomolecules (extracellular polysaccharides, peptidoglycans and proteins) or refractory humic aggregates (Kaplan et al., 1987; Lee et al., 1996; Hung et al., 2001; Lead and Wilkinson, 2006). In the Xin'an River, the removal behavior of $\mathrm{Cu}$ did not occur. On the contrary, the addition of three colloidal fractions indicated that the metal addition was stronger than colloidal coagulation/flocculation in this region, which could be attributed to the delayed flocculation of the colloid by the strong Cu-ligands added from the sediment (Skrabal et al., 1997; Santos-Echeandia et al., 2008). In addition, as the study by Baeyens et al. (1998) in the Scheldt estuary, the contribution of suspended particles desorption to $\mathrm{Cu}$ addition should not be ignored.

\subsection{3. $\mathrm{Pb}$}

In the Xin'an River, the percentages of colloidal $\mathrm{Pb}$ were always at a low level ( $\leq 15.9 \%$ of the total dissolved pool), and the percentage change of each colloidal fraction (from salinity $\sim 0$ to salinity 30) was not as obvious as that of the Guangdang River (Fig. 4e, f and $9 \mathrm{e}, \mathrm{f}$ ). Although the variations of colloidal $\mathrm{Pb}$ in the Xin'an River are not dramatic (compared with the Guangdang River), in the lower salinity zone (from 0.3 to 24.0 ), the addition could be found in the 1-10 kDa fractions of the two rivers (Fig. 4e, $\mathrm{f}$ and Fig. 5e, f). However, except for the 3-10 kDa colloidal $\mathrm{Pb}$, the other colloidal fraction of $\mathrm{Pb}$ showed similar removal in both estuaries (Fig. 4e, $\mathrm{f}$ and Fig. 5e, f). In general, $\mathrm{Pb}(<0.45 \mu \mathrm{m})$ had a significant correlation with Fe $(<0.45 \mu \mathrm{m})$ in the estuary area $\left(R^{2}=0.33\right.$, $p<0.01, \mathrm{n}=72$, Waeles et al., 2007), and Wen et al. (1999) found that high-molecular-weight $(>10 \mathrm{kDa})$ colloidal $\mathrm{Pb}$ was often accompanied by Fe-oxides. Therefore, Luoma (1989) proposed that the main carrier of colloidal $\mathrm{Pb}$ may be the colloid-Fe-oxides or colloid-Fe-sulphides complex, and the flocculation of Fe caused by the intense river-sea mixing in the estuary area may directly lead to the limitation of $\mathrm{Pb}$ in the estuary area (Benoit et al., 1994).

\section{Conclusions}

In this study, a separation and determination method of aquatic colloidal $\mathrm{Cd}, \mathrm{Cu}$ and $\mathrm{Pb}$ was established by CUF, acid extraction and ICP-MS. By precisely adjusting the centrifugation time and centrifugal force, the colloidal metal of different molecular weights in 6 samples could be effectively separated within $70 \mathrm{~min}$. In addition, combined with ICP-MS, lower LOD (0.005-0.131 $\left.\mathrm{nmol} \mathrm{L}^{-1}\right)$ and excellent recoveries (85.3-100.8\%) were obtained. Membrane calibration experiments were also performed and the results showed that the difference between manufacturer-rated and actual MWCO would overestimate the colloidal metal concentration of each fraction in the water sample.

After using the modified method for the analysis of the water samples of Yantai City, Eastern China, it could be found that Cd, $\mathrm{Cu}$ and $\mathrm{Pb}$ in the truly dissolved phase accounted for $58-90 \%$ of the total dissolved pool. In addition, $\mathrm{Cd}$ and $\mathrm{Pb}$ were more likely to bind to the $10 \mathrm{kDa}-0.2 \mu \mathrm{m}$ colloids, while $\mathrm{Cu}$ was related to the 1-3 kDa LMW colloids. By studying the size distribution variations of the trace metals along the salinity gradient, the data 
explain the dynamic behaviors of the three metals in the lower salinity zone (from $\sim 0.3$ to $\sim 27$ ) and estuary area $(\sim 30)$. Briefly, the addition of dissolved $\mathrm{Cd}$ (in the low salt zone) involves the formation of $\mathrm{Cl}$-complexes and desorption or degradation of particulate matters, and this addition is more pronounced in winter and is strongly correlated with the $1-10 \mathrm{kDa}$ colloids. The removal behaviors of 1-10 kDa Cd in the Guangdang estuary could be attributed to the coagulation/flocculation of the colloid. As for $\mathrm{Cu}$, the removal behaviors in the Guangdang estuary may be the reduction of strong $\mathrm{Cu}$-ligands and the coagulation/flocculation of colloids, and the intriguing additions in the Xin'an estuary may be the reason for the strong Cu-ligands introduced into the water by sediments. As a metal with strong correlation with Fe-oxides, removal behaviors of $\mathrm{Pb}$ at the two estuaries are significantly controlled by the coagulation/flocculation of Fe-oxides. In summary, due to the high heterogeneity of colloidal metals, detailed descriptions of various factors are needed to better understand the dynamic migration processes and biogeochemical cycling of the elements in aquatic systems, especially along the river-sea continuum.

\section{Declaration of Competing Interest}

The authors declare that they have no known competing financial interests or personal relationships that could have appeared to influence the work reported in this paper.

\section{Acknowledgements}

We thank the anonymous reviewers for their helpful comments. This study was supported by the Strategic Priority Research Program of the Chinese Academy of Sciences (XDA23050303) and the National Natural Science Foundation of China (41376083).

\section{Appendix A. Supplementary data}

Supplementary data to this article can be found online at https://doi.org/10.1016/j.scitotenv.2019.135265.

\section{References}

Apte, S.C., Gardner, M.J., Ravenscroft, J.E., 1990. An investigation of copper complexation in the Severn estuary using differential pulse cathodic stripping voltammetry. Mar. Chem. 29, 63-75.

Baeyens, W., Goeyens, L., Monteny, F., Elskens, M., 1998. Effect of organic complexation on the behavior of dissolved $\mathrm{Cd}, \mathrm{Cu}$ and $\mathrm{Zn}$ in the Scheldt estuary. Hydrobiologia 366, 81-90.

Benoit, G., Oktay-Marshall, S.D., Cantu, A., Hood, E.M., Coleman, C.H., Corapcioglu, M.O., Santschi, P.H., 1994. Partitioning of $\mathrm{Cu}, \mathrm{Pb}, \mathrm{Ag}, \mathrm{Zn}, \mathrm{Fe}, \mathrm{Al}$, and $\mathrm{Mn}$ between filter-retained particles, colloids, and solution in six Texas estuaries. Mar. Chem. 45, 307-336.

Burba, P., Aster, B., Nifanteva, T., Shkinev, V., Spivakov, B.Y., 1998. Membrane filtration studies of aquatic humic substances and their metal species: a concise overview: Part 1. Analytical fractionation by means of sequential-stage ultrafiltration. Talanta 45, 977-988.

Byrne, R.H., Yao, W.S., 2000. Formation of palladium(II) hydroxychloride complexes and precipitates in sodium chloride solutions and seawater. Geochim. Cosmochim. Acta 64, 4153-4156.

Colombo, C., Oates, C.J., Monhemius, A.J., Plant, J.A., 2008. Complexation of platinum, palladium and rhodium with inorganic ligands in the environment. Geochem. Explor. Environ. A 8, 91-101.

Cornu, S., Samouëlian, A., Ayzac, A., Montagne, D., 2018. Soluble and colloidal translocation of $\mathrm{Al}, \mathrm{Fe}, \mathrm{Si}$ and $\mathrm{Mn}$ in an artificially drained French Retisol. Geoderma 330, 193-203.

Dai, M.H., Martin, J.M., 1995. First data on trace metal level and behavior in two major Arctic river-estuarine systems (Ob and Yenisey) and in the adjacent Kara Sea, Russia. Earth Planet. Sci. Lett. 131, 127-141.

Elsohaby, I., McClure, J., Riley, C.B., Bryanton, J., Bigsby, K., Shaw, R.A., 2018 Centrifugal ultrafiltration of human serum for improving immunoglobulin a quantification using attenuated total reflectance infrared spectroscopy. J. Pharmaceut. Biomed. 150, 413-419.

Gerringa, L.J.A., Poortvliet, T.C.W., Hummel, H., 1996. Comparison of chemical speciation of copper in the Oosterschelde and Westerschelde Estuaries, The Netherlands. Estuar. Coast. Shelf S. 42, 629-643.
Guo, L.D., Santschi, P.H., 2007. Ultrafiltration and its applications to sampling and characterisation of aquatic colloids. In: Wilkinson, K., Lead, J. (Eds.), Environmental Colloids and Particles: Behavior, Separation and Characterisation. John Wiley \& Sons Ltd., Chichester, pp. 159-221.

Guo, L.D., Wen, L.S., Tang, D.G., Santschi, P.H., 2000. Re-examination of cross flow ultrafiltration for sampling aquatic colloids: evidence from molecular probes. Mar. Chem. 69 (1), 75-90.

Hargreaves, A.J., Vale, P., Whelan, J., Constantino, C., Dotro, G., Campo, P., Cartmell, E., 2017. Distribution of trace metals ( $\mathrm{Cu}, \mathrm{Pb}, \mathrm{Ni}, \mathrm{Zn}$ ) between particulate, colloidal and truly dissolved fractions in wastewater treatment. Chemosphere $175,239-246$.

Huang, L.L., Pu, X.M., Pan, J.F., Wang, B., 2013. Heavy metal pollution status in surface sediments of Swan Lake lagoon and Rongcheng Bay in the northern Yellow Sea. Chemosphere 93, 1957-1964.

Hung, C.C., Tang, D., Warnken, K.W., Santschi, P.H., 2001. Distributions of carbohydrates, including uronic acids, in estuarine waters of Galveston Bay. Mar. Chem. 73, 305-318.

Jin, Y.Q., Guo, L.M., Song, J.R., Yang, J.X., Liu, H.L., Chen, W.B., 2007. The content measurement of V-B 12 by UV-Vis. J. Changzhi Med. Coll. 21 (4), 251-253 (In Chinese with English abstract).

Kaplan, D., Christiaen, D., Arad (Malis), S., 1987. Chelating properties of extracellular polysaccharides from Chlorella spp. Appl. Environ. Microb. 53, 2953-2956.

Kawakami, S.K., Gledhill, M., Achterberg, E.P., 2006. Production of phytochelatins and glutathione by marine phytoplankton in response to metal stress. J. Phycol. 42, 975-989.

Kozelka, P.B., Bruland, K.W., 1998. Chemical speciation of dissolved Cu, Zn, Cd, Pb in Narragansett Bay, Rhode Island. Mar. Chem. 60, 267-282.

Lead, J.R., Wilkinson, K.J., 2006. Natural aquatic colloids: current knowledge and future trends. Environ. Chem. 3, 159-171.

Lee, J.G., Ahner, B.A., Morel, F.M.M., 1996. Export of cadmium and phytochelatin by the marine diatom Thalassiosira weissflogii. Environ. Sci. Technol. 30, 18141821.

Li, L., Liu, J.H., Wang, X.J., Shi, X.F., 2015. Dissolved trace metal distributions and Cu speciation in the southern Bohai Sea. China. Mar. Chem. 172, 34-45.

Liu, R., Lead, J.R., 2006. Partial validation of cross flow ultrafiltration by atomic force microscopy. Anal. Chem. 78, 8105-8112.

Liu, R.X., Lead, J.R., Baker, A., 2007. Fluorescence characterization of cross flow ultrafiltration derived freshwater colloidal and dissolved organic matter. Chemosphere 68, 1304-1311.

Liu, R.X., Lead, J.R., Zhang, H., 2013. Combining cross flow ultrafiltration and diffusion gradients in thin-films approaches to determine trace metal speciation in freshwaters. Geochim. Cosmochim. Acta 109, 14-26.

Loginov, M., Samper, F., Gésan-Guiziou, G., Sobisch, T., Lerche, D., Vorobiev, E., 2017 Centrifugal ultrafiltration for determination of filter cake properties of colloids. J. Membr. Sci. 536, 59-75.

Lu, Y.X., Gao, X.L., Chen, C.T.A., 2019. Separation and determination of colloidal trace metals in seawater by cross-flow ultrafiltration, liquid-liquid extraction and ICP-MS. Mar. Chem. https://doi.org/10.1016/j.marchem.2019.103685.

Luoma, S.N., 1989. Can we determine the biological availability of sediment-bound trace elements?. Hydrobiologia 176 (177), 379-396.

Martin, J.M., Dai, M.H., 1995. Significance of colloids in the biogeochemical cycling of organic carbon and trace metals in the Venice lagoon (Italy). Limnol. Oceanogr. 40 (1), 119-131.

Pokrovsky, O.S., Shirokova, L.S., Zabelina, S.A., Vorobieva, T.Y., Moreva, O.Y., Klimov, S.I., Chupakov, A.V., Shorina, N.V., Kokryatskaya, N.M., Audry, S., Viers, J., Zoutien, C., Freydier, R., 2012. Size fractionation of trace elements in a seasonally stratified boreal lake: control of organic matter and iron colloids. Aquat. Geochem. 18, 115-139.

Santos-Echeandia, J., Laglera, L.M., Prego, R., van den Berg, C.M.G., 2008. Dissolved copper speciation behavior during estuarine mixing in the San Simon Inlet (wet season, Galicia). Influence of perticulate matter. Estuar. Coast. Shelf S. 76, 447453.

Skrabal, S.A., Donat, J.R., Burdige, D.J., 1997. Fluxes of copper-complexing ligands from estuarine sediments. Limnol. Oceanogr. 42, 992-996.

Sun, B., Li, H.X., Fan, Q., Sun, S., Ren, Q., Kong, Q.M., Zhao, X., 2015. Application of ultrafiltration on aqueous two-phase extraction technique. J. Northeast Agric. Univ. 45 (4), 101-108 (In Chinese with English abstract).

Tang, D., Warnken, K.W., Santschi, P.H., 2001. Organic complexation of copper in surface waters of Galveston Bay. Limnol. Oceanogr. 46, 321-330.

Waeles, M., Riso, R.D., Le Corre, P., 2005. Seasonal variations of cadmium speciation in the Penzé estuary, NW France. Estuar. Coast. Shelf S. 65, 143-152.

Waeles, M., Riso, R.D., Le Corre, P., 2007. Distribution and seasonal changes of lead in an estuarine system affected by agricultural practices: The Penzé estuary, NW France. Estuar. Coast. Shelf S. 570-578.

Waeles, M., Tanguy, V., Lespes, G., Riso, R.D., 2008. Behaviour of colloidal trace metals $(\mathrm{Cu}, \mathrm{Pb}$ and $\mathrm{Cd})$ in estuarine waters: An approach using frontal ultrafiltration (UF) and stripping chronopotentiometric methods (SCP). Estuar. Coast. Shelf S. 80, 538-544.

Wells, M.L., Kozelka, P.B., Bruland, K.W. 1998. The complexation of "dissolved" Cu, $\mathrm{Zn}, \mathrm{Cd}$ and $\mathrm{Pb}$ by soluble and colloidal organic matter in Narragansett Bay, RI. Mar. Chem. 62, 203-217.

Wen, L.S., Stordal, M.C., Tang, D.G., Gill, G.A., Santschi, P.H., 1996. An ultraclean cross-flow ultrafiltration technique for the study of trace metal phase speciation in seawater. Mar. Chem. 55, 129-152.

Wen, L.S., Santschi, P.H., Warnken, K.W., Davison, W., Zhang, H., Li, H.P., Jiann, K.T. 2011. Molecular weight and chemical reactivity of dissolved trace metals ( $\mathrm{Cd}$ 
$\mathrm{Cu}, \mathrm{Ni}$ ) in surface waters from the Mississippi River to Gulf of Mexico. Estuar. Coast. Shelf S. 92, 649-658.

Xu, H.C., Guo, L.D., 2017. Molecular size-dependent abundance and composition of dissolved organic matter in river, lake and sea waters. Water Res. 117, 115-126.

Xu, H.C., Houghton, E.M., Houghton, C.J., Guo, L.D., 2018. Variations in size and composition of colloidal organic matter in a negative freshwater estuary. Sci. Total Environ. 615, 931-941.

Zhang, Y., Gao, X.L., Wang, C.Y., Chen, C.T.A., Zhou, F.X., Yang, Y.W., 2016. Geochemistry of phosphorus in sediment cores from Sishili Bay, China. Mar. Pollut. Bull. 113 (1-2), 552-558.
Zhang, Z.P., Sun, X.J., Chi, Q.Q., Zhu, G.W., Qin, B.Q., 2007. Concentrations of colloidal trace metals in Lake Taihu in spring. Environ. Chem. 26 (2), 232-235 (In Chinese with English abstract).

Zhou, Z.Z., Guo, L.D., 2015. A critical evaluation of an asymmetrical flow field-flow fractionation system for colloidal size characterization of natural organic matter. J. Chromatogr. A 1399, 53-64.

Zhou, Z.Z., Stolpe, B., Guo, L.D., Shiller, A.M., 2016. Colloidal size spectra, composition and estuarine mixing behavior of DOM in river and estuarine waters of the northern Gulf of Mexico. Geochim. Cosmochim. Acta 181, 1-17. 